\title{
Isotache model for consolidation with a small incremental load
}

1 Hiroyuki Tanaka DEng

Professor, Hokkaido University, Sapporo, Japan (corresponding author: tanaka@eng.hokudai.ac.jp)
2 Ayato Tsutsumi DEng

Engineer, Penta-Ocean Construction Co., Ltd, Tokyo, Japan
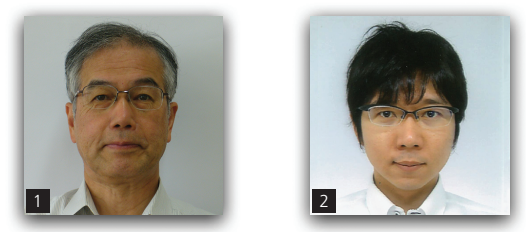

To examine the applicability of an isotache model, two types of consolidation test were carried out: constant rate of strain (CRS) by changing the strain rate during the test, and an incremental loading (IL) test with small incremental ratios. It is found from the CRS tests that the stress shift caused by the strain rate change is nearly the same for all tested soils, but the behaviour after the change is different: some soils do not follow the isotache model. After selecting two typical soils (one follows the isotache model and the other does not), IL tests with various increment ratios and different durations at the loading stage prior to the incremental load were carried out to investigate how these parameters affect the strain-time relation. It is revealed that the strain-time relation is strongly governed by the magnitude of stress increments; in cases of small increments, most of the settlement is generated after the end of the primary consolidation. It is found that most test results can be interpreted by the isotache model. However, when the load duration at the loading stage prior to the incremental load is longer, the time-strain behaviour differs from that predicted by the isotache model.

\section{Notation}

$C_{\mathrm{c}} \quad$ compression index

e void ratio

G shear modulus

$I_{\mathrm{p}} \quad$ plasticity index

$K_{\mathrm{o}} \quad$ coefficient of earth pressure at rest

$k_{0} \quad$ hydraulic conductivity after the first loading

$p \quad$ effective pressure

$p_{1} \quad p$ just before changing strain rate from $3 \times 10^{-6} / \mathrm{s}$

$R \quad$ stress change ratio caused by ten times strain rate change

$T_{\mathrm{V}} \quad$ time factor

$t_{90}$ time for $90 \%$ of consolidation

$U$ degree of consolidation

$u_{\mathrm{b}} \quad$ pore water pressure measured at the bottom in CRS test

$w_{\mathrm{L}} \quad$ liquid limit

$\alpha \quad$ ratio of $\Delta \varepsilon / \Delta \log \dot{\varepsilon}$

$\Delta p \quad$ incremental load in IL test

$\Delta p_{\mathrm{r}} \quad$ stress shift due to strain rate change

$\varepsilon \quad$ strain

$\dot{\varepsilon} \quad$ strain rate

$\varepsilon_{(\mathrm{p})} \quad$ strain generated during secondary consolidation

\section{Introduction}

The Terzaghi type of consolidation theory is widely employed for the calculation of ground settlement in practice, assuming that a volume change of soil is caused only by increasing effective stresses - that is, the dissipation of the excess pore water pressure. In this conventional model, the volume change is derived from the $e-\log p$ ( $e$ : void ratio; $p$ : pressure) curve measured by an incremental loading (IL) oedometer test where the incremental load ratio $(\Delta p / p)$ is 1 , and its duration at each loading stage is $24 \mathrm{~h}$. It is usual that a settlement after the dissipation of the excess pore water pressure, which is sometimes called secondary consolidation or creep, is not considered in this calculation. It is well recognised that the accuracy of this calculation method is very high for reclamation in coastal areas in Japan. However, it has been reported that the prediction by the conventional Terzaghi method considerably underestimated the observed settlement at the Kansai International Airport (e.g. Kobayashi et al. (2005)). The ground at this site consists of a single Holocene and several Pleistocene clayey layers, and a large discrepancy between the measured and calculated settlements was observed in the Pleistocene clayey layers.

It is well known that the $\Delta p / p$ ratio for IL tests strongly affects the shape of the time-displacement curve, as shown in Figure 1 


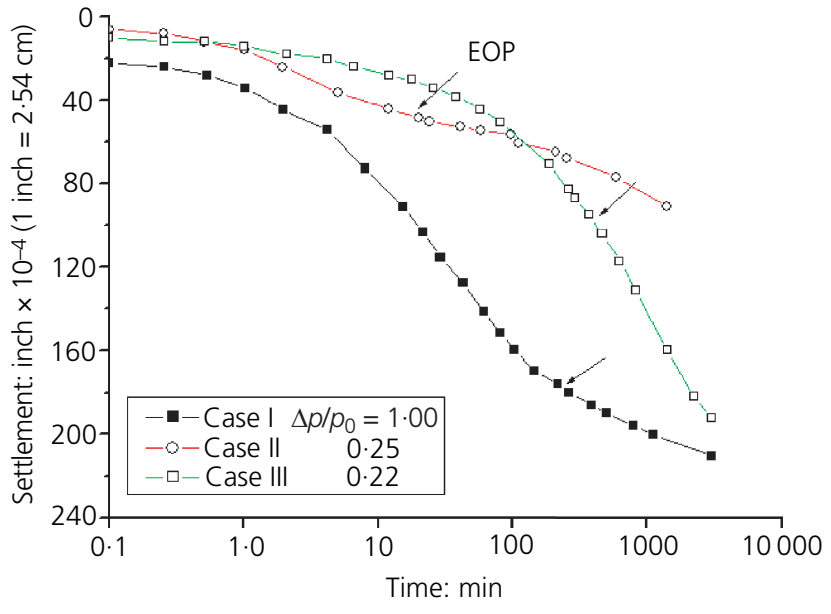

Figure 1. Influence of stress incremental ratio on the shape of relation between time and compression (data from Leonards and Altschaeffl (1964); 1 inch $=2.54 \mathrm{~cm}$ )

(Leonards and Altschaeffl, 1964). In Leonards and Altschaeffl's (1964) tests, the excess pore water pressure was measured, and the time for the dissipation of the excess pore water pressure that is, the end of primary (EOP) consolidation - is indicated by the arrow in Figure 1. The curve for consolidation with a large $\Delta p / p$ ratio (case I in the figure) is very similar to the $U-T_{\mathrm{v}}$ curve calculated by Terzaghi's method, where $U$ and $T_{\mathrm{v}}$ are the degree of consolidation and the time factor, respectively. Although a small amount of settlement after the EOP is observed, most of the total settlement is generated during the primary consolidation that is, by the change in the effective stress. In contrast, when small $\Delta p / p$ is applied, a considerable amount of settlement is generated after the EOP, in particular for case III in Figure 1. These different patterns of the settlement curve due to different $\Delta p / p$ ratios may be explained by the isotache model, where the stress-strain relation is defined not only by the effective stress, but also by the strain rate $(\dot{\varepsilon})$ (Suklje, 1957). According to this model, since the magnitude of the strain caused by a change in the strain rate is independent of the absolute applied load, the secondary settlement is relatively large for small $\Delta p / p$ because the settlement due to the change in the effective stress is small. On the other hand, the influence of the secondary consolidation with large $\Delta p / p$ ratios is relatively small or can be ignored.

This explanation can be useful when considering the difference between observed and calculated settlements at the Kansai International Airport. Indeed, the settlement measured in the Holocene clay layer agreed fairly well with the predicted one, because the weight of the fill material at this site was considerably larger than the on-site effective overburden stress before the filling - that is, $\Delta p / p$ was large, where $\Delta p$ and $p$ correspond to the fill weight and the in situ vertical effective stress prior to the filling, respectively. However, for the Pleistocene clay layers deposited in greater depths, the in situ effective stress was much greater, while $\Delta p$ was largely the same as for the shallower Holocene layer. The
$\Delta p / p$ ratio hence becomes small with depth, and the loading condition becomes similar to case II or III in Figure 1. In most previous reclamation works in Japan, the Pleistocene clay layer did not exist or its thickness was very small. However, at the site of the Kansai airport, the total thickness of the Pleistocene layer exceeded $200 \mathrm{~m}$ so that the amount of settlement caused by secondary consolidation in these layers may be considerably large. Indeed, Kobayashi et al. (2005) reported that the calculation method taking account of the strain rate effect could well predict the settlement at the Kansai airport site.

In the isotache model, the strain rate dependency - that is, the shift of the effective stress due to a change in the strain rate - is a key feature. Figure 2 illustrates briefly the concept of the isotache model. In this figure, the $\varepsilon-\log p$ relationship is indicated by a family of straight lines according to the strain rate (ESRL is the equi-strain rate line, and $\mathrm{ESRL}_{0}$ is a line for the reference strain rate of $3 \times 10^{-6} / \mathrm{s}$ in this study). However, the linearity in the $\varepsilon-\log p$ relationship is not necessary, but a point in the isotache model is that they are parallel to each other - that is, $R=\Delta p_{\mathrm{r}} / p$ is constant, where $\Delta p_{\mathrm{r}}$ is the stress shift due to the change in strain rate and $p$ is the stress before the change in the strain rate. An $\varepsilon-\log p$ relationship in a constant rate of strain (CRS) oedometer test follows one of several lines in Figure 2 according to a predetermined strain rate, while in the IL test, the strain after the EOP increases following the strain rate theory by the isotache model. The strain rate dependency can be measured by a CRS test with different strain rates or by an IL test with long-term consolidation (see, for example, Tanaka (2005) and Watabe et al. (2008)). However, a considerably long time is required in an IL test to observe the strain rate dependency at strain rate levels less than $10^{-9} / \mathrm{s}$, and a CRS test needs more time for completion at such slow strain rates (for example, $1000 \mathrm{~d}$ are required in order to attain $10 \%$ strain at $10^{-9} / \mathrm{s}$ ). Instead of these conventional methods for obtaining the strain rate dependency, Tsutsumi and Tanaka (2011) tried to carry out a special CRS, where a specimen was subjected not to a single fixed strain rate but to multiple different strain rates (see Figure 2). If the stress-strain relation immediately transferred to a new $\varepsilon-\log p$ relationship by a

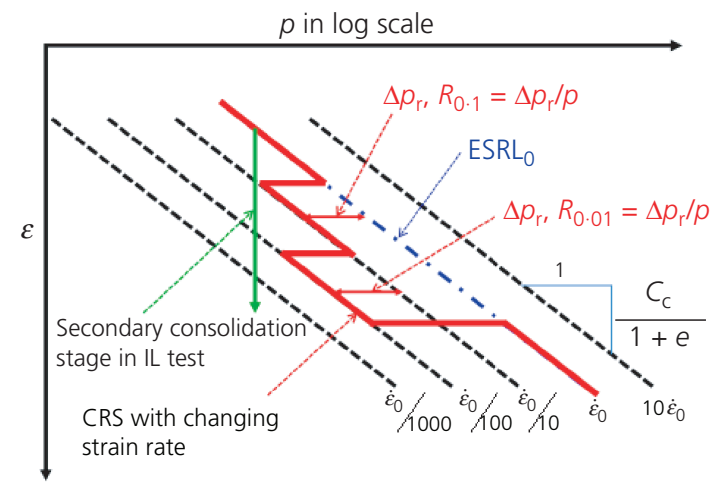

Figure 2. Concept of isotaches model and comparison of CRS and IL tests 
change in the strain rate, the strain rate dependency at various strain rate levels can be evaluated by a reasonable testing time in this method. However, as will be mentioned later in more detail, although the $\varepsilon-\log p$ relationships shifted consistently in response to the strain rate change in their tests, the soil did not always behave as predicted by the isotache model, but there was a trend to come back to the original relationship before the shift. Such non-isotache behaviour was strongly dependent on soil types, although what properties or indices govern its behaviour were not clearly identified in their study.

\section{Strain rate dependency from CRS}

Soil samples and testing method

Table 1 gives the main geotechnical properties of the samples used in this study. The test was performed for both intact and reconstituted conditions. The name of the samples for the reconstituted condition is identified by ' $R e$ ' at the end of the sample name, and those without 'Re' are intact samples. The reconstituted samples were made by thoroughly mixing soils with water to reach a water content about two times the liquid limit $\left(w_{\mathrm{L}}\right)$. Then, samples were $K_{\mathrm{o}}$ consolidated in a cell under a consolidation pressure of $100 \mathrm{kPa}$.

Since the testing method employed in this study was described in detail in previous papers (Tsutsumi and Tanaka, 2011, 2012), this paper briefly introduces the testing procedure. The diameter of the specimen was $60 \mathrm{~mm}$, and its initial height was $20 \mathrm{~mm}$. The bottom of the specimen was undrained, and the pore water pressure $\left(u_{\mathrm{b}}\right)$ was measured. The upper face of the specimen was kept drained. A back pressure of $100 \mathrm{kPa}$ was applied for high saturation. The most important point in this test was to adopt a step motor for axial loading that is controlled by a personal computer and whose resolution is as accurate as 2621440 pulses per revolution. Therefore, the loading machine can be controlled precisely to a predetermined strain rate and can be changed immediately from the present strain rate to a slower or faster rate. Since the excess pore water pressure is generated in the specimen during the test, the average effective stress $(p)$ should be calculated. For the conventional CRS test, the $p$ is calculated by in the following equation, assuming that the distribution of the excess pore water pressure is parabolic

1. $p=\sigma-\frac{2}{3} \Delta u_{\mathrm{b}}$

where $\sigma$ is the measured stress by a load cell and $\Delta u_{\mathrm{b}}$ is the excess pore water pressure measured at the bottom.

To avoid the effects of the bedding error on the lower and upper surfaces of the specimen or a gap between the oedometer ring and the specimen, the specimen was compressed to exceed the preconsolidation stress and reach more than $5 \%$ of the strain at $3 \times 10^{-6} / \mathrm{s}$. Then the strain rate was changed to predetermined strain rates. The test was carried out under a temperature of $20^{\circ} \mathrm{C}$.

\begin{tabular}{|c|c|c|c|c|c|}
\hline Name & Area & $w_{n}: \%^{a}$ & $W_{L}: \%$ & $W_{p}: \%$ & $I_{\mathrm{p}}$ \\
\hline OsakaMa10 & Kansai, Japan & $45 \cdot 8$ & 82 & 32 & 50 \\
\hline Louiseville & Quebec, Canada & $81 \cdot 5$ & 81 & 24 & 57 \\
\hline OsakaMa12 & Kansai, Japan & $61 \cdot 2$ & 92 & 38 & 54 \\
\hline OsakaMa13 & Kansai, Japan & $74 \cdot 2$ & 95 & 39 & 56 \\
\hline Takuhoku & Hokkaido, Japan & $65 \cdot 1$ & 70 & 25 & 46 \\
\hline Yangsan & Busan, Korea & $61 \cdot 5$ & 67 & 26 & 41 \\
\hline Drammen & Norway & $43 \cdot 4$ & 45 & 21 & 24 \\
\hline Onsoy & Norway & $59 \cdot 4$ & 76 & 25 & 51 \\
\hline Bothkennar & Scotland, UK & $68 \cdot 5$ & 62 & 27 & 35 \\
\hline OsakaMa12Re & Kansai, Japan & $87 \cdot 4$ & 109 & 43 & 66 \\
\hline OsakaMa13Re & Kansai, Japan & $70 \cdot 7$ & 91 & 38 & 53 \\
\hline KasaokaRe & Okayama, Japan & $46 \cdot 2$ & 62 & 36 & 26 \\
\hline HachirogataRe & Akita, Japan & $180 \cdot 9$ & 246 & 96 & 150 \\
\hline TokyoRe & Tokyo, Japan & $95 \cdot 6$ & 108 & 36 & 72 \\
\hline YamashitaRe & Yokohama, Japan & $105 \cdot 8$ & 115 & 69 & 46 \\
\hline YangsanRe & Busan, Korea & $48 \cdot 5$ & 63 & 23 & 40 \\
\hline LouisevilleRe & Quebec, Canada & $46 \cdot 9$ & 71 & 22 & 49 \\
\hline
\end{tabular}

${ }^{a} w_{n}$ for Re is that of reconstituted sample

Table 1. Main properties of soils used in the CRS test with changing strain rate 


\section{Test results}

Figure 3 shows the influence of the change in the strain rate on the $\varepsilon-\log p$ relationship for four samples, as typical examples. For the first two samples - that is, OsakaMa13Re and KasaokaRe - the strain rate in the first phase was $3 \times 10^{-6} / \mathrm{s}$, then decreased to $1 / 10$ times that is, $3 \times 10^{-7} / \mathrm{s}-$ and, furthermore, dropped to $3 \times 10^{-8} / \mathrm{s}$. The strain rate was finally brought back to the original rate of $3 \times 10^{-6} / \mathrm{s}$. For OsakaMa10 and LouisevilleRe (Figures 3(c) and 3(d)), the strain rate was decreased furthermore to $3 \times 10^{-9} / \mathrm{s}$. The vertical axis indicates the incremental strain from the decreasing strain rate $(\Delta \varepsilon)$. The effective stress $(p)$ is normalised by $p_{1}$, which is the effective stress just before changing the strain rate from $3 \times 10^{-6} / \mathrm{s}$. For all the samples, the strain rate dependency is clearly observed - that is, when the strain rate decreases, the $p$ decreases, while when the strain rate increases, the $p$ increases. However, only OsakaMa10 clay exactly follows the isotache model - that is, after changing the strain rate, the $\Delta \varepsilon-\log p / p_{1}$ relationship is parallel to the relationship before changing the strain rate. For other clays, the $\Delta \varepsilon-\log p / p_{1}$ relationships at different strain rates are not parallel to that at $3 \times 10^{-6} / \mathrm{s}$, and when the strain rate comes back from $3 \times 10^{-8}$ or $3 \times 10^{-9}$ to $3 \times 10^{-6} / \mathrm{s}$, the $\Delta \varepsilon-\log p / p_{1}$ relationship considerably exceeds the relationship for the original strain rate. As increasing the strain, however, $\Delta \varepsilon-\log p / p_{1}$ is gradually approaching and finally joined to the original relation.

To characterise the $\Delta \varepsilon-\log p / p_{1}$ relationship at the change in the strain rate, a stress ratio $\left(R=\Delta p_{\mathrm{r}} / p\right)$ is defined (see Figure 2), where $p$ is the effective stress just before the strain rate is changed, and $\Delta p_{\mathrm{r}}$ is the shift of stress due to the change in the strain rate. Furthermore, to distinguish $R$ at various different strain rates, $R_{0 \cdot 1}$ will be used for the case that the strain rate is changed from $3 \times 10^{-6}$ to $3 \times 10^{-7} / \mathrm{s}$, while $R_{0.01}$ will be used for the case that the strain rate is changed from $3 \times 10^{-7}$ to $3 \times 10^{-8} / \mathrm{s}$. In addition, the reference $\mathrm{ESRL}_{0}$ is defined, which is a supposed $\Delta \varepsilon-\log p$ relationship under the strain rate of $3 \times 10^{-6} / \mathrm{s}$ without the change in the strain rate. $\mathrm{ESRL}_{0}$ is defined by assuming that the line can be expressed by a cubic function, and its more detailed procedure is given by Tsutsumi and Tanaka (2011). ESRL ${ }_{0}$ is shown in the form of $\Delta \varepsilon-\log p / p_{1}$ in Figure 3. If the $\Delta \varepsilon-\log p$ relationship after changing the strain rate does not follow the isotache model and it tends to approach to the $\mathrm{ESRL}_{0}$, the distance of the $\mathrm{ESRL}_{0}$ from the point of the strain rate change from $3 \times 10^{-7}$ to $3 \times 10^{-8} / \mathrm{s}$ is different from that corresponding to the change from $3 \times 10^{-6}$ to

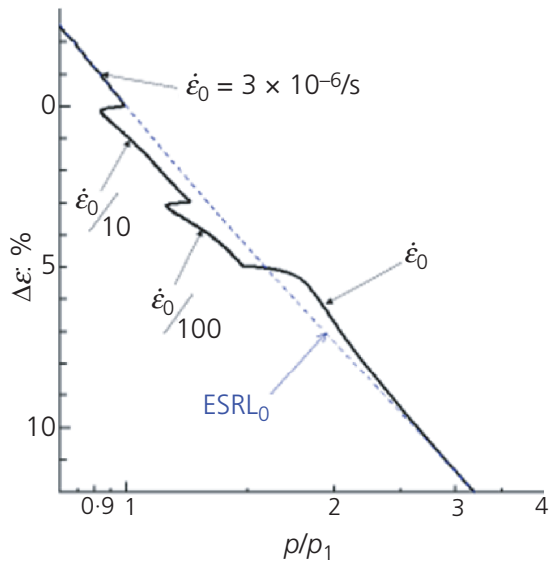

(a)

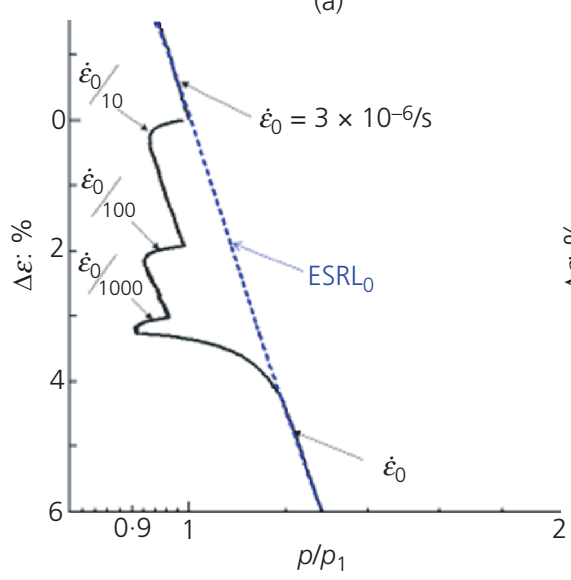

(c)

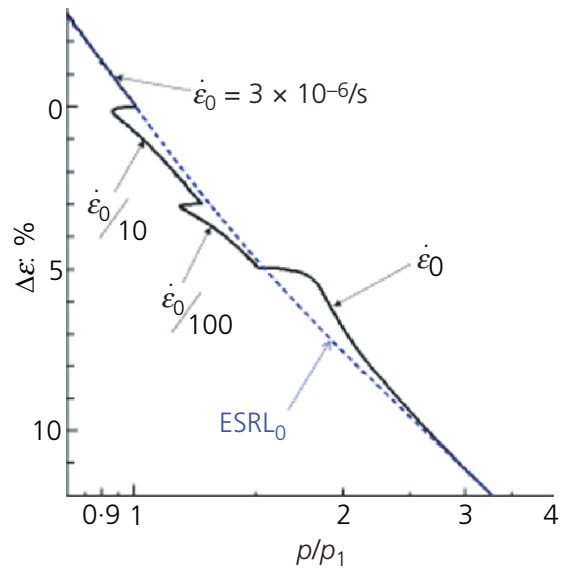

(b)

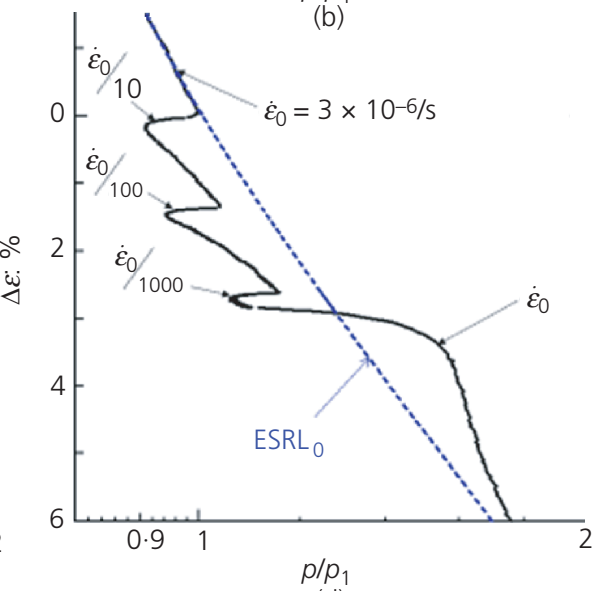

(d)

Figure 3. $\Delta \varepsilon-\log p$ relationship after changing the strain rate.

(a) OsakaMa13Re; (b) KasaokaRe; (c) OsakaMa10; (d) LouisevilleRe 
Isotache model for consolidation with a

small incremental load

Tanaka and Tsutsum

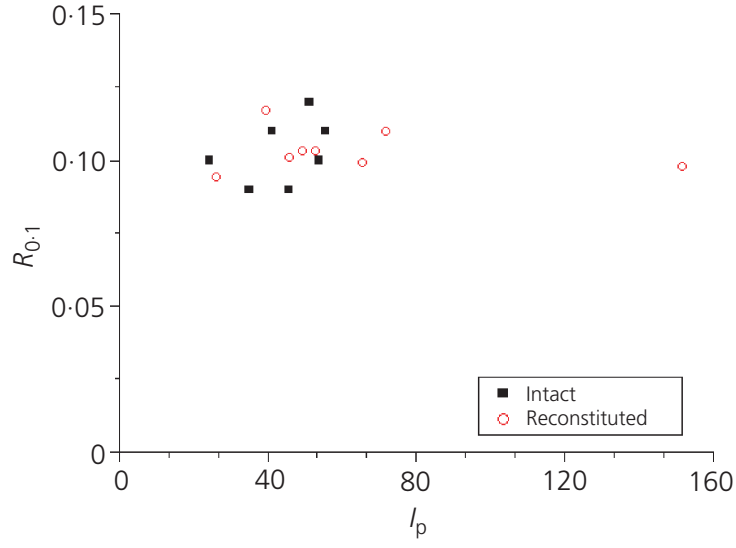

Figure 4. Influence of $I_{p}$ on the shift of the effective stress $\left(R_{0.1}\right)$

$3 \times 10^{-7} / \mathrm{s}$. However, it seems that the $R_{0 \cdot 01}$ is not influenced by the distance from $\mathrm{ESRL}_{0}$ and the value of $R_{0 \cdot 01}$ is the same as $R_{0 \cdot 1}$. Many similar tests were carried out for different soils as listed in Table 1 , and $R_{0 \cdot 1}$ values are plotted against the plasticity index $\left(I_{\mathrm{p}}\right)$ in Figure 4, and their correlation of $R_{0 \cdot 1}$ and $R_{0.01}$ is in Figure 5. It can be seen in these figures that not only $R_{0 \cdot 01}$ and $R_{0 \cdot 1}$ for all samples are nearly the same, but also the absolute values of $R_{0 \cdot 1}$ and $R_{0.01}$ are about $0 \cdot 1$, regardless of types of the sample. Furthermore, as shown in OsakaMa10 and LouisevilleRe, $R_{0 \cdot 1}$ and $R_{0.001}$ (the stress ratio corresponding to strain rate changes from $3 \times 10^{-8}$ to $3 \times 10^{-9} / \mathrm{s}$ ) have approximately the same values.

There are two possibilities for causing the non-isotache behaviour: acceleration of strain and structuring. In these tests, the strain rate was suddenly changed. During the transition phase from a faster strain rate to a slower rate, the specimen was subjected to a large negative acceleration. There may be a possibility that such a high acceleration generates an excessive reduction of the stress. In the same way, the overshooting behaviour of the $\Delta \varepsilon-\log p^{\prime}$ observed

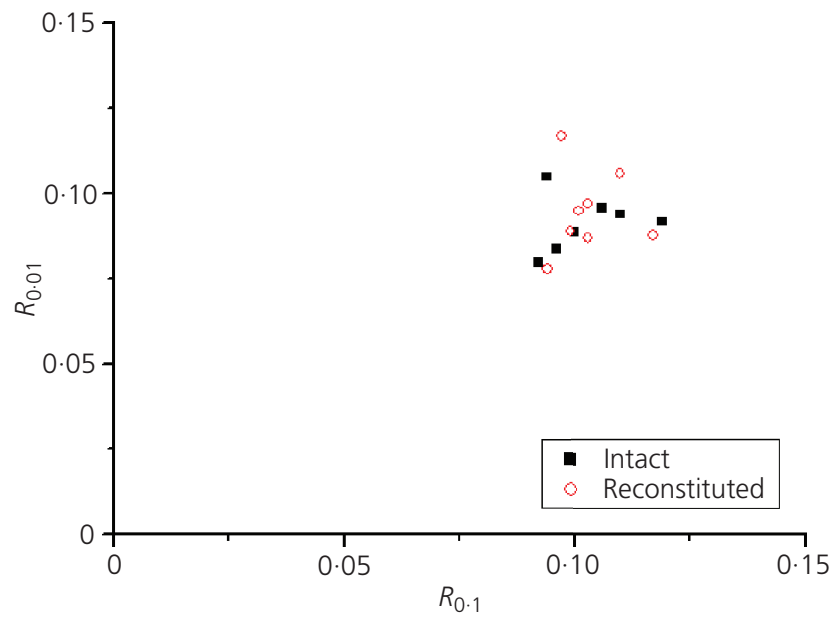

Figure 5. Comparison of $R_{0 \cdot 1}$ and $R_{0.01}$ from the slower to the faster strain rates can be explained by a large positive acceleration. However, such a large acceleration is generated in a very short period of this transition, and in the other moments, the acceleration is completely null. Therefore, it is unlikely that this acceleration having acted in a short period brings persistent non-isotache behaviour. An alternative explanation is the development of a new structure to resist the deformation. It can be interpreted that when the sample slowly deforms under small strain rates, there is enough time to create a new structure. This structure becomes effective at a large strain rate and shows a large yield stress, but it will be gradually destroyed by further compression. Leroueil et al. (1985) carried out a series of CRS tests with different but constant $\dot{\varepsilon}$ and reported that the stress-strain relation at $1.69 \times 10^{-8} / \mathrm{s}$ was completely different from those at other faster strain rates. They concluded that this different behaviour at $1.69 \times 10^{-8} / \mathrm{s}$ is attributed to the effect of structuring. If this assumption is accepted, the soil behaviour during consolidation consists of two components: a 'true' strain rate dependency and creation of the structure; and the former does not seem to be different for soils because $R$ is nearly same (see in Figures 4 and 5).

Figure 6 may provide a good example to understand the structure created under the slow strain rate conditions. The CRS tests reported in the figure were carried out on KasaokaRe at two different temperatures, 10 and $50^{\circ} \mathrm{C}$, and the strain rate was changed from $3 \times 10^{-6}$ to $3 \times 10^{-8} / \mathrm{s}$ and returned to $3 \times 10^{-6} / \mathrm{s}$. The detailed procedure may be found in Tsutsumi and Tanaka (2012). It can be seen that the $\Delta \varepsilon-\log p / p_{1}$ relationship at a low temperature nearly follows the isotache model, but as temperature rises to $50^{\circ} \mathrm{C}$, the tendency of non-isotache behaviour becomes prominent. This implies that the structure is likely to develop more rapidly at a higher temperature. It is interesting to note that

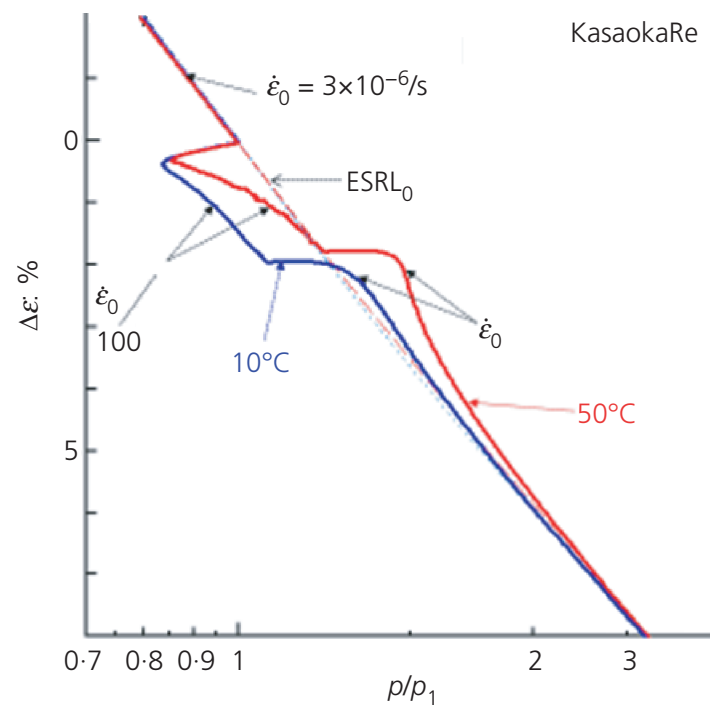

Figure 6. Influence of temperature on the strain rate dependency (data from Tsutsumi and Tanaka (2012)) 
even though the behaviour after the strain rate changes is completely different at the two temperatures, the magnitude of the shift of $\Delta p_{\mathrm{r}}$, in other words $R$, is nearly the same. It should be also noted that the non-isotache behaviour is more prominent at slower strain rate (see, for example, Figure 3(d)). These observations suggest that the structure for resisting deformation is likely to be developed under a high temperature and needs a sufficient time (low strain rate). Marques et al. (2002) carried out similar CRS tests, but with fixed strain rates. They also pointed out the importance of temperature effect on the creation of the structure.

The purpose of this paper is to show how the effect of structure, which is observed in the CRS test, explains the behaviour in IL tests with relatively small $\Delta p / p$. For this purpose, Louiseville and OsakaMa10 are suitable samples to identify the effects on the strain and time relationship measured by the IL tests, as they exhibited typical non-isotache and isotache behaviours, respectively. Unfortunately, however, the available amount of these clays was not enough to create reconstitute samples, so KasaokaRe and OsakaMa13Re were selected. As seen in Figures 3(a) and 3(b), KasaokaRe presents much more nonisotache behaviour than OsakaMa13Re. Keeping this difference in mind, the test results from the IL tests will be examined and discussed in the next section.

\section{IL test results with different incremental loading ratios}

\section{Soil samples and testing procedures}

As described in the previous section, two types of soil showing different behaviours after changing the strain rate were selected and their properties are given in Table 2. All the specimens were made by reconstitution to focus on the different compression behaviours caused by different stress increments $(\Delta p / p)$. The consolidation test was carried out by following JIS A 1217:2009 (JSA, 2009) (test method for one-dimensional consolidation properties of soils using incremental loading), except for the incremental loading ratio and the duration at each loading stage. The diameter of the specimen was $60 \mathrm{~mm}$, and its initial height was $20 \mathrm{~mm}$. Drainage was allowed at both the upper and lower surfaces of the specimen. The load was applied by weights for avoiding problems such as disruption of electricity supply during the long test duration. The specimen was submerged during the test, and the temperature was kept constant at $20^{\circ} \mathrm{C}$.

\begin{tabular}{lcccc}
\hline Name & $\rho_{\mathrm{s}}: \mathrm{g} / \mathrm{cm}^{3}$ & $e_{\mathrm{o}}$ & $C_{\mathrm{c}}$ & $k_{\mathrm{o}}: \mathrm{m} / \mathrm{s}$ \\
\hline KasaokaRe & 2.610 & 0.83 & 0.468 & $2.0 \times 10^{-10}$ \\
OsakaMa13Re & 2.693 & 1.47 & 0.700 & $2.4 \times 10^{-10}$
\end{tabular}

Table 2. Main geotechnical properties used for the incremental loading test
The specimen was firstly consolidated at $260 \mathrm{kPa}$ for KasaokaRe and at $294 \mathrm{kPa}$ for OsakaMa13Re, and this process will be called 'the first loading stage'. These consolidation pressures are large enough to erase the influence of the pre-consolidation stress from the reconstituted processes - that is, the specimen is completely in a normally consolidated state. The duration in the first loading was 1, 3 and $7 \mathrm{~d}$ for KasaokaRe to investigate the influence of the duration on the consolidation behaviour in the next loading stage, while for OsakaMa13Re the duration of the first loading was fixed at $7 \mathrm{~d}$. After these durations, a small incremental load $(\Delta p)$ was applied, and this stage was called 'the second loading'. In this study, the amount of $\Delta p$ at the second loading stage is relatively small so that any differences in the tested specimen will give important influences on the test result, even though the specimen was carefully created by the reconstitution procedures. Therefore, the strain $(\varepsilon)$ is calculated, based on the thickness of the specimen on the first loading at $24 \mathrm{~h}$, not on the initial height. The initial void ratio $\left(e_{\mathrm{o}}\right)$ in Table 2 corresponds to the state at $24 \mathrm{~h}$ of the first loading stage. The consolidation index $\left(C_{\mathrm{c}}\right)$ and the hydraulic conductivity $\left(k_{\mathrm{o}}\right)$ in Table 2 were obtained by CRS tests and determined as the values at the same stress level as the first loading process. Since the change in $e$ is small enough in this test due to the small incremental ratio, $k_{\mathrm{o}}$ and $C_{\mathrm{c}}$ will be treated as constant.

\section{Consolidation behaviour for the first loading}

In this study, as already mentioned in Section 3.1, the specimen was consolidated from $100 \mathrm{kPa}$ pre-consolidation pressure to $260 \mathrm{kPa}$ for KasaokaRe and to $294 \mathrm{kPa}$ for OsakaMa13Re. Figure 7 shows the test results from the first loading stage, where duration of was $40 \mathrm{~d}$ for OsakaMa13Re and $80 \mathrm{~d}$ for KasaokaRe. It can be seen in Figure 7(a) that relationship between the strain rate $(\dot{\varepsilon})$ and the elapsed time is very similar for two clays. The relationship between the strain and $\log \dot{\varepsilon}$ is shown in Figure 7(b). In this figure, values of $\varepsilon$ for both clays are negative at $\dot{\varepsilon}$ larger than about $10^{-7} / \mathrm{s}$, since $\varepsilon$ was calculated based on the specimen height after $24 \mathrm{~h}$ of consolidation, as has already been mentioned. This relationship is clearly different for tested soils in contrary to Figure 7(a). For OsakaMa13Re, the strain changes linearly with $\log \dot{\varepsilon}$ and the gradient of $\Delta \varepsilon / \Delta \log \dot{\varepsilon}$ is significantly larger than that for KasaokaRe. There is a possibility that the bilinearity relationship between the strain and $\log \dot{\varepsilon}$ for KasaokaRe was caused by the incompletion of consolidation. If the excess pore pressure is not fully dissipated, the strain is also generated by the increase in the effective stress. However, the EOP could not be directly confirmed because the pore water pressure was not measured in these tests. Instead of the observation of the dissipation of the excess pore water pressure, the EOP is represented by the time for $90 \%$ of consolidation $\left(t_{90}\right)$, obtained by the square root method.

It is found from the $\varepsilon$-time relationship that the time of $t_{90}$ is $0.83 \mathrm{~h}$ for KasaokaRe and $0.5 \mathrm{~h}$ for OsakaMa13Re, and the values of $\dot{\varepsilon}$ at these times are $6.2 \times 10^{-6}$ and $4.0 \times 10^{-6} / \mathrm{s}$, respectively (see Figure 7(a)). It can be judged that for the most 


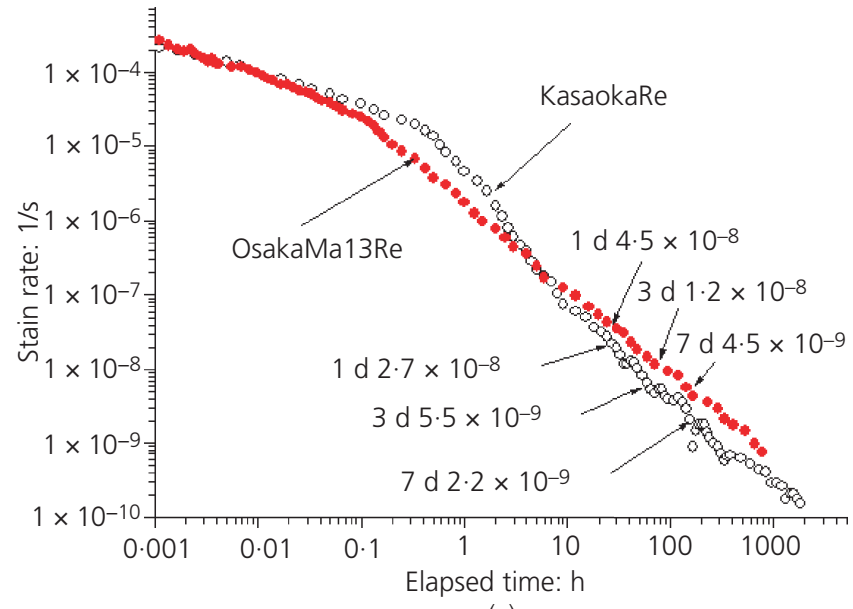

(a)

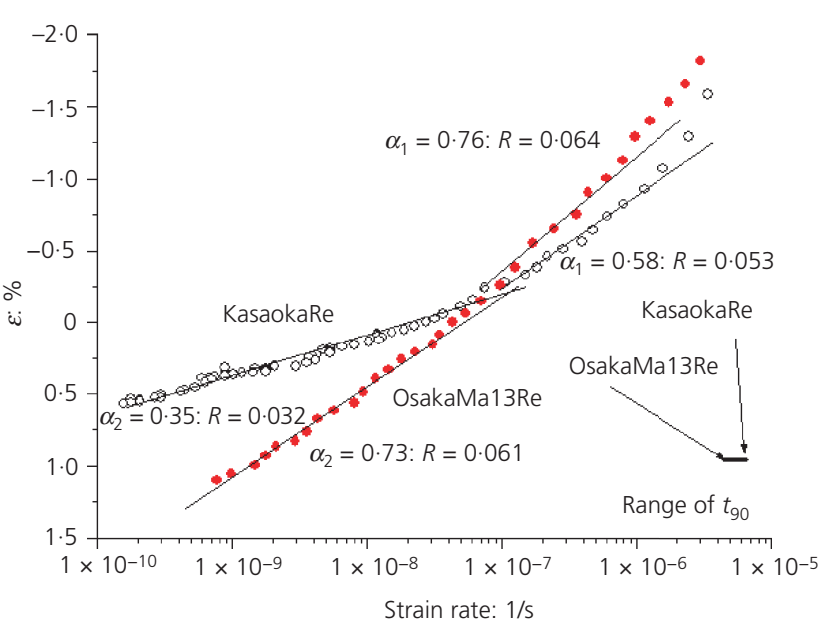

(b)

Figure 7. Relationship between strain and strain rate, measured by the first loading. (a) Relationship between strain rate and elapsed time; (b) relationship between strain and strain rate

part of the $\varepsilon-\log \dot{\varepsilon}$ relationship, the effective stress in Figure 7(b) is constant, and large $\Delta \varepsilon / \Delta \log \dot{\varepsilon}$ at faster $\dot{\varepsilon}$ than $10^{-7} / \mathrm{s}$ for KasaokaRe clay is not caused by the change in the effective stress, but probably by the nature of the soil type. This point will be discussed later in more detail.

Figure 8 shows the starting points of the second loading tests for different durations of the previous loading (the first loading) stage by solid circles and ESRL for $\dot{\varepsilon}$ of $10^{-7} / \mathrm{s}$ and corresponding strain rates of 1,3 and $7 \mathrm{~d}$, assuming that the slope of ESRL that is, $C_{\mathrm{c}}-$ is same at every strain rate.

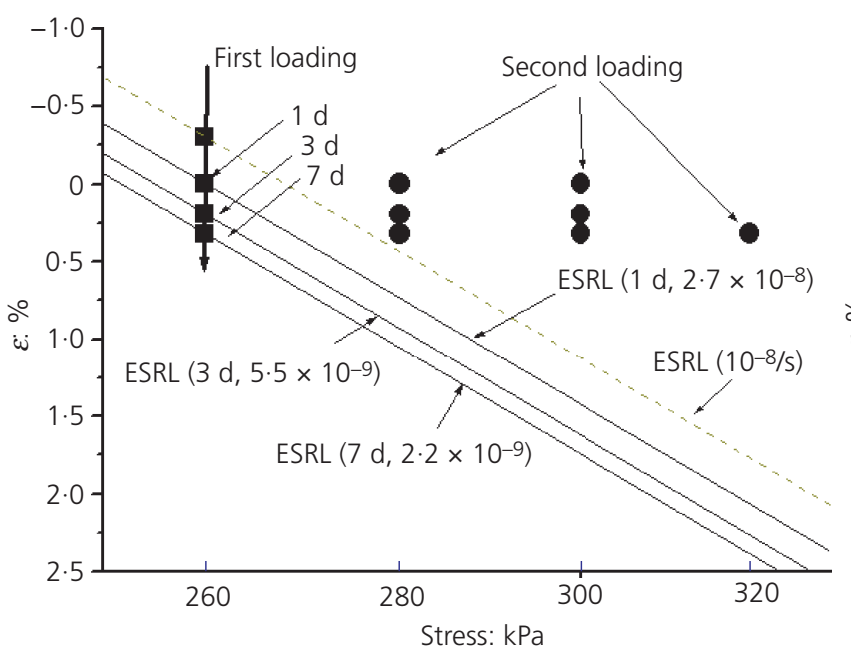

(a)
Consider the strain rate dependency - that is, the stress shift caused by changing the strain rate measured by the IL tests. The slope of $\alpha=\Delta \varepsilon / \Delta \log \dot{\varepsilon}$ in Figure 7(b) can be correlated by $R$, which is measured by CRS tests under different strain rates, referring to Figure 2

$$
\begin{aligned}
\frac{\Delta \varepsilon}{\Delta \log \dot{\varepsilon}} & =\frac{C_{\mathrm{c}}}{\left(1+e_{\mathrm{o}}\right)} \log \left(\frac{p+\Delta p_{\mathrm{r}}}{p}\right) \\
& =\frac{C_{\mathrm{c}}}{1+e_{\mathrm{o}}} \log (1+R)
\end{aligned}
$$

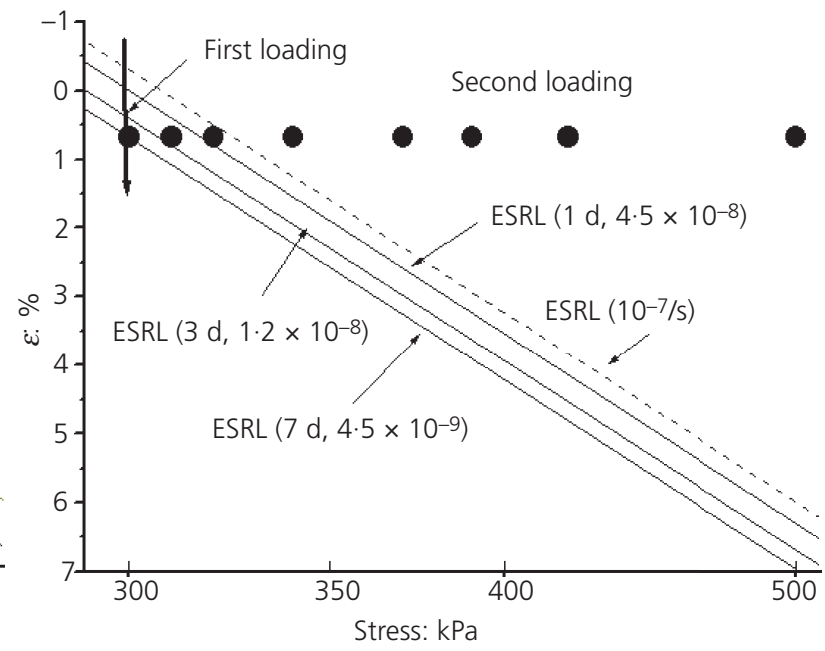

(b)

Figure 8. Stress conditions of the first and second loading stages and ESRLs with various strain rates. (a) KasaokaRe; (b) OsakaMa13Re 
The values of $\Delta \varepsilon / \Delta \log \dot{\varepsilon}$ obtained from Figure 7(b) - that is, $\alpha_{1}$ and $\alpha_{2}$ - correspond to the level of the strain rate for $R_{0 \cdot 1}$ and $R_{0.01}$, which is the $\Delta p_{\mathrm{r}} / p$ ratio caused by the change in the strain rate, from $3 \times 10^{-6}$ to $3 \times 10^{-7} / \mathrm{s}$ and from $3 \times 10^{-7} / \mathrm{s}$ to $3 \times$ $10^{-8} / \mathrm{s}$, respectively. The values of $R$ at different strain rate levels including $R_{0.001}$ were calculated using Equation 2, using $e_{\mathrm{o}}$ and $C_{\mathrm{c}}$ in Table 2. Table 3 indicates the calculated $R$, together with $R$ based on the relationship proposed by Watabe et al. (2012) in following equation

3.

$$
\ln \left(\frac{p_{\mathrm{c}}^{\prime}-p_{\mathrm{cL}}^{\prime}}{p_{\mathrm{cL}}^{\prime}}\right)=c_{1}+c_{2} \ln \dot{\varepsilon}_{\mathrm{vp}}
$$

In their equation, the strain rate dependency is expressed by the yield consolidation pressure $\left(p_{\mathrm{c}}^{\prime}\right)$ at various strain rate, and $p_{\mathrm{cL}}^{\prime}$ is the $p_{\mathrm{c}}^{\prime}$ value when the strain rate is infinitely small. Although the strain rate in their equation is defined by the plastic strain $\left(\varepsilon_{\mathrm{vp}}=\right.$ $\varepsilon_{\mathrm{t}}-\varepsilon_{\mathrm{e}}$, where $\varepsilon_{\mathrm{t}}$ and $\varepsilon_{\mathrm{e}}$ are the total and elastic strains, respectively), $\varepsilon_{\mathrm{e}}$ is not generated in the IL tests after the end of the primary consolidation because of the constant load applied. Based on many data accumulated from the site of the Kansai International Airport, the constants of $c_{1}$ and $c_{2}$ were determined. In addition, they have revealed that this equation is applicable to not only the Osaka Bay clay, but also various worldwide clays accumulated in their database. In this study, $R$ was calculated assuming that the change in the $p_{\mathrm{c}}^{\prime}$ value be equivalent to $\Delta p_{\mathrm{r}}$. It is seen in the table that the order of $R$ calculated using Equation 3 is the same as for OsakaMa13Re, because this clay belongs to the Osaka Bay clay. However, $R$ for KasaokaRe is clearly smaller than that for OsakaMa13Re. In particular when the strain rate is smaller, the difference becomes prominent. It should be recalled that $R$ obtained by the CRS test is about $0 \cdot 1$ regardless of the soil types (see Figures 4 and 5) and the strain rate level (see Figures 3(c) and $3(\mathrm{~d})$ ). In contrary, $R$ estimated by the IL tests in this study as well as calculated using Equation 3 decreases with a decrease in the strain rate. This trend for KasaokaRe is in particular significant. This result is not inconsistent with the fact that KasaokaRe exhibits more strongly non-isotache behaviour; in other words, KasaokaRe more significantly develops a structure to resist the deformation. Furthermore, it can be inferred that the non-linearity of the $p_{\mathrm{c}}^{\prime}$ and $\dot{\varepsilon}$ relationship as seen in Equation 3, or the decrease in $R$ with $\dot{\varepsilon}$ in the IL tests, is caused by the structure created during the secondary consolidation. It may be considered that at a very small strain rate, the compression caused by the incremental load and resistance caused by structuring are complicatedly entangled.

\section{Consolidation behaviour for the second loading with small incremental loading ratio}

Figure 9 shows the relationships between $\Delta \varepsilon$ and elapsed time measured from the second loading stage. It should be noted that the strain of $\Delta \varepsilon$ in these figures is an incremental strain based on $\varepsilon$ just at the beginning of second loading. The relationship in Figure 9(a) is for KasaokaRe clay, and the duration of the first loading stage is 7. As $\Delta p$ becomes larger, the $\Delta \varepsilon$ is also larger. The shape of the $\Delta \varepsilon$ and time relationship is similar to case II or III of the tests conducted by Leonards and Altschaeffl (1964) in Figure 1. The time for the EOP estimated by $t_{90}$ and indicated by an arrow in the figure is very short, and most settlement is generated in the secondary consolidation. Figure 9(b) indicates the influence of the duration of the first loading stage on the behaviour observed at the second loading stage. In this test series, $\Delta p$ is fixed as $20 \mathrm{kPa}$. The times for the EOP are shorter than $0.01 \mathrm{~h}$, and they are not indicated in the figure. As expected, the longer the duration of the first loading stage is, the smaller the observed settlement is.

Figure 9(c) shows the test results from OsakaMa13Re, where the wide range of $\Delta p$ was applied, but the duration of the first loading was fixed as $7 \mathrm{~d}$. Because of the wide range of $\Delta p / p^{\prime}$ in this test, the strain is normalised by that after $24 \mathrm{~h}\left(\Delta \varepsilon_{\mathrm{at} 24 \mathrm{~h}}\right)$ in Figure 9(c). The slope of the $\Delta \varepsilon / \Delta \varepsilon_{\mathrm{at} 24 \mathrm{~h}}-\log t$ relationship for the small $\Delta p$ monotonically increases, while as $\Delta p$ becomes larger, the slope is initially small and then decreases again after a certain time (see, for example, the relationship for $\Delta p$ larger than $90 \mathrm{kPa}$ ). However, this turning point does not correspond to the EOP. For example, for a case of $\Delta p=200 \mathrm{kPa}$, this point is attained at $10 \mathrm{~h}$, but the primary consolidation is completed at $0 \cdot 1 \mathrm{~h}$. The so-called $3 \mathrm{t}$ method is extensively used for confirming the end of consolidation in laboratory tests in Japan (for example, JGS 0522-2009 (JGS, 2009)). In the $3 \mathrm{t}$ method, the time for consolidation is determined as three times the time of this turning point. This method can be applied only in the case of large $\Delta p / p$, when the stress conditions enter completely the normal consolidation state. However, for example, if the recompression method is to be employed where the specimen is consolidated at the in situ stress conditions, the 3 t method cannot be used to confirm that the consolidation is completed.

\begin{tabular}{lccc}
\hline Sample name & $R_{0.1}$ & $R_{0.01}$ & $R_{0.001}$ \\
\cline { 2 - 4 } & $3 \times 10^{-6}$ to $3 \times 10^{-7}$ & $3 \times 10^{-7}$ to $3 \times 10^{-8}$ & $3 \times 10^{-8}$ to $3 \times 10^{-9}$ \\
\hline KasaokaRe & 0.077 & 0.048 & 0.032 \\
OsakaMa13Re & 0.090 & 0.074 & 0.075 \\
Watabe et al. (2012) & 0.086 & 0.074 & 0.062
\end{tabular}

Table 3. Strain rate dependency derived by IL oedometer test 


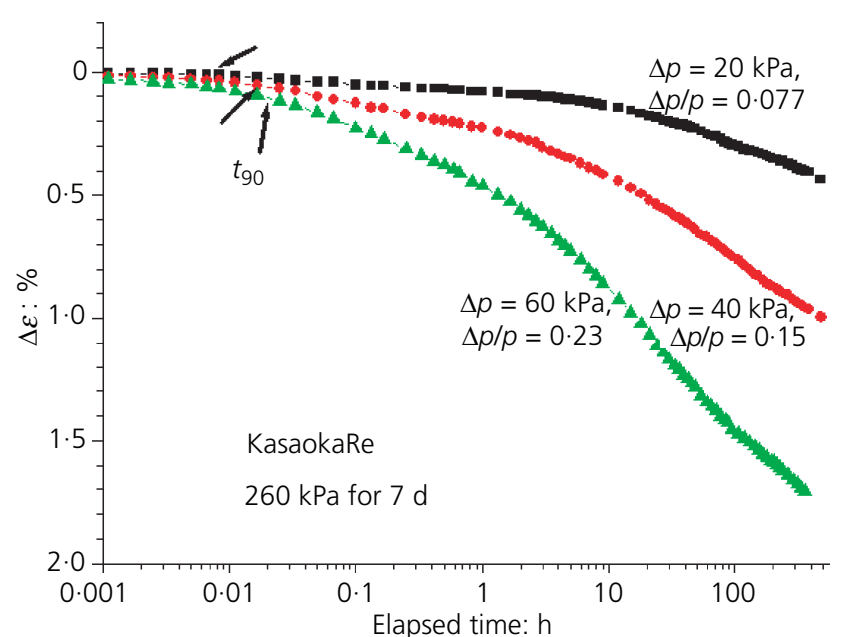

(a)

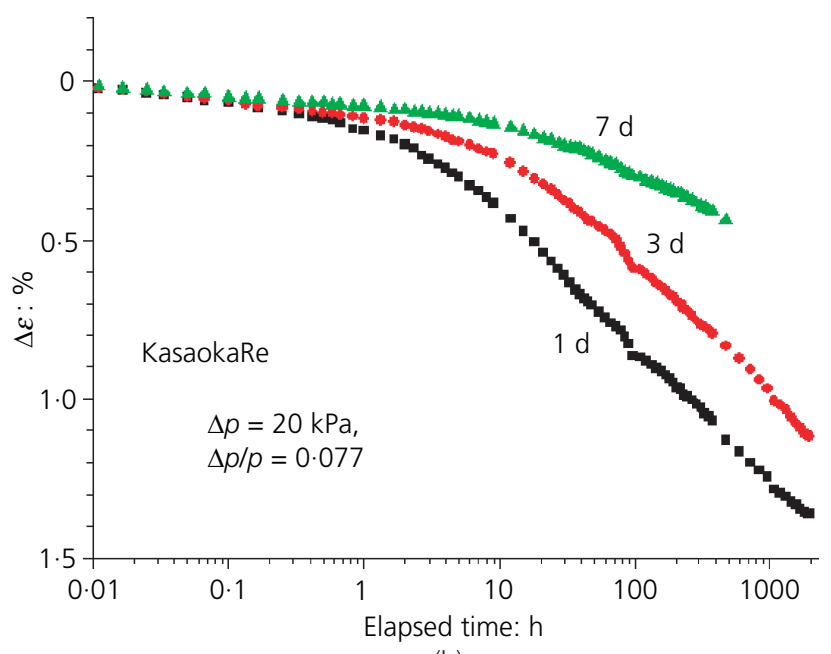

(b)

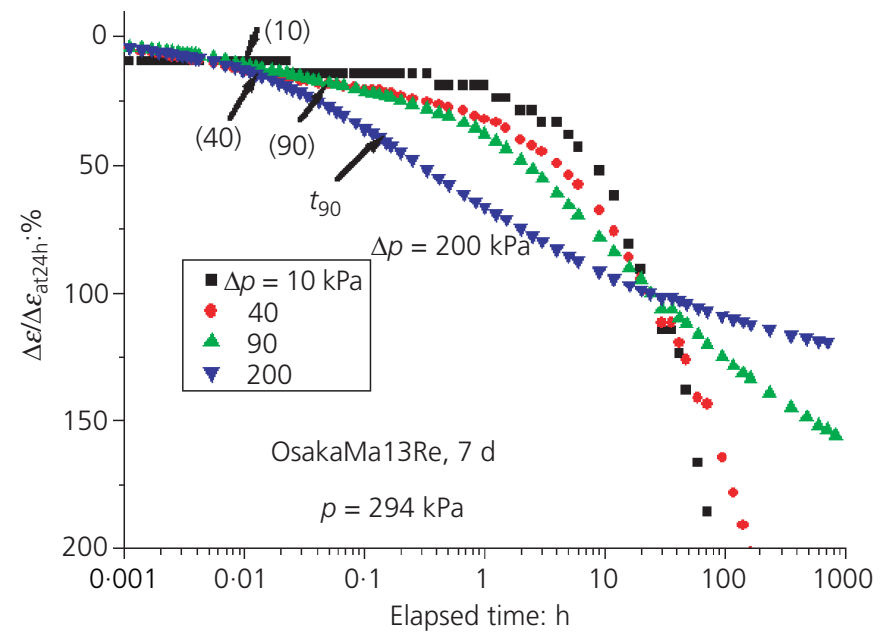

(c)

Figure 9. Time and strain (measured at the second loading) relationship with various incremental loads. (a) KasaokaRe - the duration of the first loading stage is $7 \mathrm{~d}$; (b) KasaokaRe - the incremental load is $20 \mathrm{kPa}$; (c) OsakaMa13Re - the duration of the first loading stage is $7 \mathrm{~d}$. The strain is normalised by the strain at $24 \mathrm{~h}$
Now examine whether the specimen with small incremental stress ratios follows the isotache behaviour. For this purpose, a new parameter, $\varepsilon_{(\mathrm{p})}$, which means a strain generated during secondary consolidation due to the strain rate dependency, will be introduced to eliminate the influence of the increase in the effective stress and is defined by the following equation.

4. $\varepsilon_{(\mathrm{p})}=\varepsilon-\frac{C_{\mathrm{c}}}{\left(1+e_{\mathrm{o}}\right)} \log \left(\frac{p+\Delta p}{p}\right)$

where $\varepsilon$ is the strain based on the specimen thickness at $1 \mathrm{~d}$ of the first loading stage, as previously defined, and $p$ is the consolidation pressure of the first loading - that is, $260 \mathrm{kPa}$ for KasaokaRe and $294 \mathrm{kPa}$ for OsakaMa13Re. $C_{\mathrm{c}}$ and $e_{\mathrm{o}}$ are given in Table 2.
The relationship between $\varepsilon_{(\mathrm{p})}$ and $\log \dot{\varepsilon}$ is presented in Figure 10(a) for OsakaMa13Re and in Figure 10(b) for KasaokaRe. It should be reminded that if the soil behaviour exactly follows isotache, $\varepsilon_{(\mathrm{p})}$ should be only correlated with the strain rate - that is, a unique relationship between $\varepsilon_{(\mathrm{p})}$ and $\dot{\varepsilon}$ exists. It seems that OsakaMa13Re exactly follows the isotache model. From Figure $8(\mathrm{~b})$, the starting point for the second loading stage for $\Delta p=$ $20 \mathrm{kPa}$ is located a little above the ESRL of $4.5 \times 10^{-8} / \mathrm{s}$, which is the strain rate measured $1 \mathrm{~d}$ after the first loading. As shown in Figure $10(\mathrm{a})$, the $\varepsilon_{(\mathrm{p})}-\log \dot{\varepsilon}$ relationship for $\Delta p=20 \mathrm{kPa}$ is nearly parallel to the horizontal axis until $\dot{\varepsilon}$ of the $2 \times 10^{-8} / \mathrm{s}$ - that is, no $\varepsilon_{(\mathrm{p})}$ is generated. Beyond this strain rate, the $\varepsilon_{(\mathrm{p})}-\log \dot{\varepsilon}$ relationship joins that of the first loading stage, $\Delta p=0$ in the figure. The strain rates at intercepted points to the relationship for $\Delta p=0$ for other cases are $1.5 \times 10^{-8}$ and $1 \times 10^{-7} / \mathrm{s}$ for $\Delta p=10$ and $40 \mathrm{kPa}$, respectively, which are consistent with those expected in the 


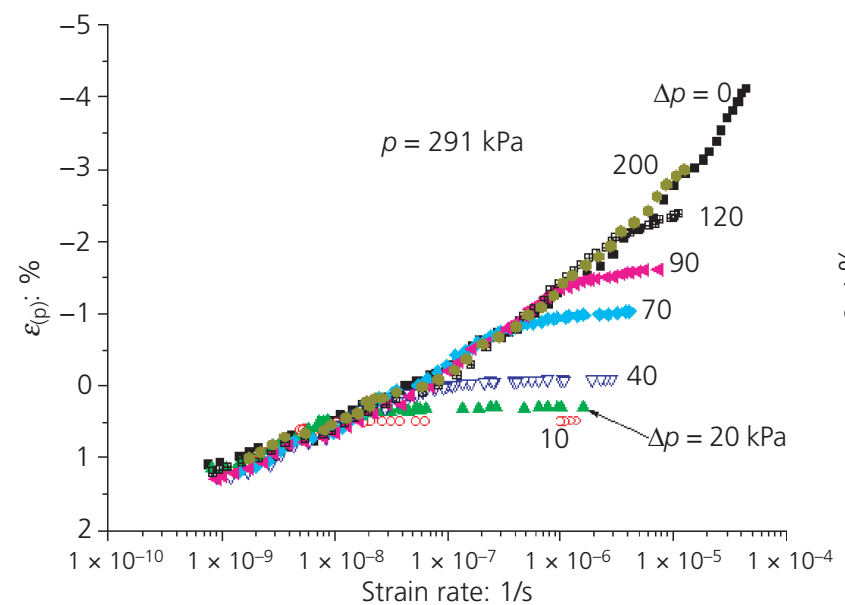

(a)

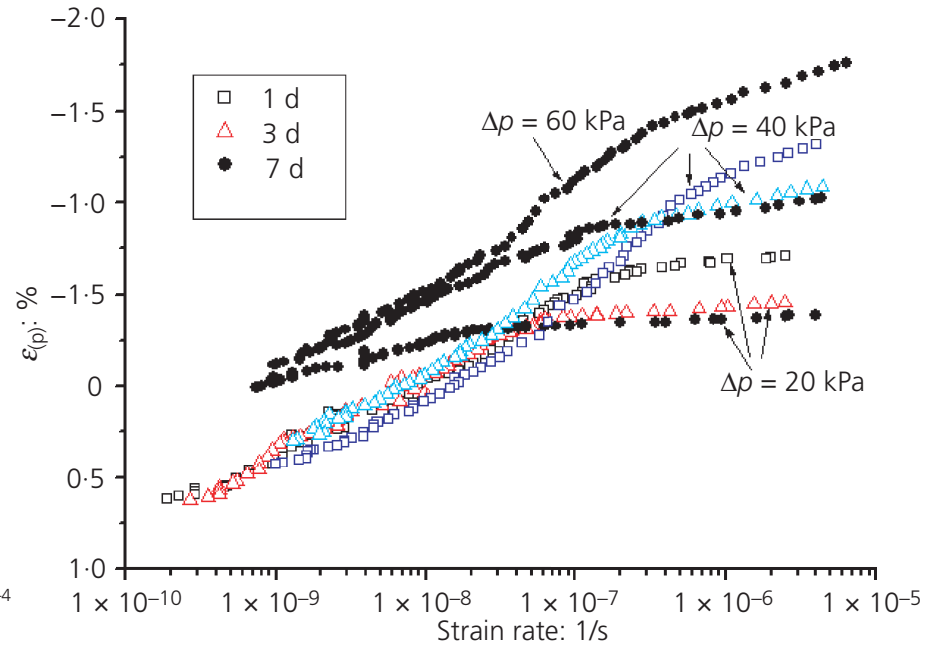

(b)

Figure 10. Isotache characteristics measured by the IL tests: (a) OsakaMa13Re; (b) KasaokaRe

isotache model (see Figure 8(b)). It is very interesting to note that in the $\varepsilon_{(\mathrm{p})}-\log \dot{\varepsilon}$ relationship for relatively large $\Delta p$, the isotache behaviour is observed even at relatively large strain rates, where the primary consolidation is not completed.

On the other hand, the behaviour of KasaokaRe is different from that of OsakaMa13Re, as shown in Figure 10(b). It can be seen that the relationships for the duration of 1 and $3 \mathrm{~d}$ of the first loading stage are the same as that for OsakaMa13Re - that is, they follow the isotache model, regardless of the magnitude of $\Delta p$. However, the relationship for $7 \mathrm{~d}$ of duration of the first loading does not coincide with the relationships mentioned earlier, but shifts upwards and is nearly parallel to those for 1 and $3 \mathrm{~d}$. The difference in $\varepsilon_{(\mathrm{p})}$ is as much as $0.5 \%$. This amount of the difference is too large to be considered as an experimental error. In addition, it is very interesting to observe the behaviour for smaller $\Delta p$ with $7 \mathrm{~d}$ of duration of the first loading stage. For example, the relationship between $\varepsilon_{(\mathrm{p})}$ and $\log \dot{\varepsilon}$ for $\Delta p=20 \mathrm{kPa}$ is expected to bend at $\dot{\varepsilon}$ of $1 \times 10^{-7} / \mathrm{s}$ according to Figure $8(\mathrm{a})$, but the relation bends in reality at $1.5 \times 10^{-8} / \mathrm{s}$, and the slope of the $\varepsilon_{(\mathrm{p})}$ and $\log \dot{\varepsilon}$ relationship after bending is much smaller than the others. These facts may imply that the structure created during the $7 \mathrm{~d}$ of the first loading and delayed the strain development. This tendency is stronger as $\Delta p$ becomes smaller. As $\Delta p$ becomes larger, the structure created at the first loading stage is destroyed. However, the original relationship between $\varepsilon_{(\mathrm{p})}$ and $\log \dot{\varepsilon}$ cannot be fully recovered, and a new relationship is developed with the strain shifted as much as $0 \cdot 5 \%$. However, it cannot be explained why 7 not $3 \mathrm{~d}$ of duration of the loading suddenly creates such a structure. It should also be reminded that OsakaMa13Re does not present such behaviours even when the duration of the first loading is $7 \mathrm{~d}$. There is a question whether such a difference is truly brought about by the difference in the $\varepsilon-\log p$ relationship after changing the strain rate (see Figures 3(a) and 3(b)). Further experimentation with different soil samples is required to confirm it.

\section{Discussion}

In considering the development of the structure, a study conducted by Seng and Tanaka (2012) is very informative. They studied an increase in shear modulus $(G)$ due to secondary consolidation and thixotropy for clay with high water content, using bender elements. Figures 11 and 12 are useful in understanding the effect of structure in this study. Figure 11 shows increases in the shear modulus after the EOP under very low consolidation stresses (from 2 to $20 \mathrm{kPa}$ ).

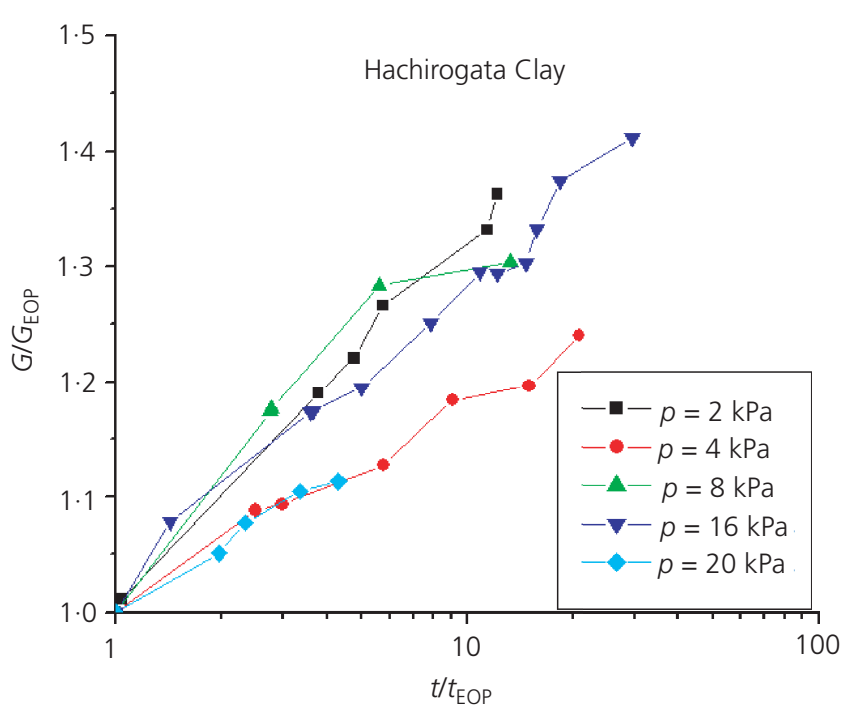

Figure 11. Increase in $G$ during the secondary consolidation (data from Seng and Tanaka (2012)) 


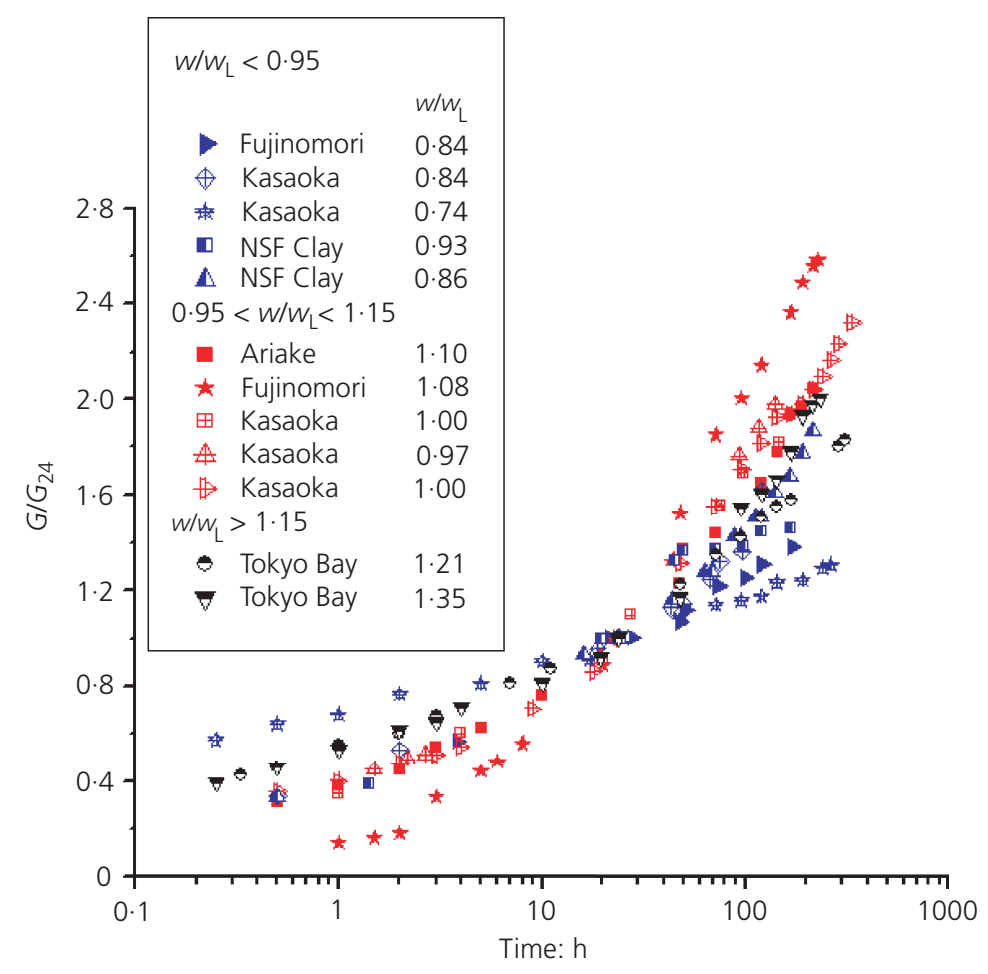

Figure 12. Increase in $G$ due to the thixitorpy effect (data from

Seng and Tanaka (2012))

In Figure 12, the increase in $G$ due to thixotropy effect is presented, where the specimen was completely remoulded and the water content was kept constant during the test (no pressure was applied except for the self-weight of the specimen). In this figure, $G$ is normalised by $G$ after $24 \mathrm{~h}\left(G_{24}\right)$. By coincidence, this $24 \mathrm{~h}$ was nearly equal to the time for the EOP of the consolidation test in Figure 11. It is observed that the increment in $G$ in Figure 12 is little affected by water content, and the increment of $G$ is most significant when the water content is around the liquid limit $\left(w_{\mathrm{L}}\right)$. It should be noted that the increment $G$ observed in the thixotropy test (Figure 12) is much larger than that in the oedometer test (Figure 11). Indeed, before starting these tests, it was anticipated that the $G$ increment during secondary consolidation should be larger than that due to the thixotropy, because the void ratio of soil gradually decreases in the secondary consolidation process, while it is constant at the thixotropy test. They have interpreted this unexpected result as follows: in the oedometer test, the structure created in the process of the secondary consolidation is destroyed by the continuous settlement, while in the thixotropy test, the structure is not destructed because of the constant void ratio (no settlement). In other words, the increase in $G$ during the secondary consolidation is not generated by decreasing the void ratio, but such a densification plays a negative role to increase in $G$.

It is well recognised that the on-site void ratio is much larger than that from a reconstituted sample that is consolidated by the same pressure (for example, Tanaka (2005)). If the settlement caused by the secondary consolidation is considered, the in situ void ratio should be smaller than that at the laboratory, because the duration of consolidation at laboratory is at most 1 month. Considering such inconsistency, Burland (1990) has distinguished the relationship between the void index and pressure for intrinsic compression line defined by $e$ at $w_{\mathrm{L}}$ and sedimentation consolidation line. These facts imply that the process of the sedimentation is considerably different from that anticipated from the conventional consolidation tests - for example, observed in the IL test - perhaps since the rate of the sedimentation in fields is generally so slow that the structuring effect becomes prominent and prevents the compression of the soil layers. As a result, despite a relatively large void ratio, natural sedimentary layer exhibits a large yield consolidation pressure.

When the result from this study is applied to field, the influence of the thickness should be considered. As already described, the thickness of the specimen used in this study is only $20 \mathrm{~mm}$. On the other hand, the thickness of the compressible layer in field is usually on the order of $10 \mathrm{~m}$ - that is, the strain rate in field is much smaller. This means that the effect of the structure observed in the field should be much stronger. Therefore, it is required to know the settlement behaviour under further slower strain rates than those in this study. However, at present, the strain rate achieved at the laboratory is at $10^{-9} / \mathrm{s}$ level at most, as seen in Figures 3(c) and 3(d). Instead of a laboratory test, it is recommended to analyse the displacement data measured in field 
with the aid of numerical calculation based on a suitable constitutive model. The authors wish to use this experimental study to establish reasonable constitutive models considering structuring effects created in the process of compression.

\section{Conclusions}

As a powerful concept to solve the settlement problems, attention has recently been paid to the isotache model, where the strain-stress relationship is governed by the strain rate. To examine the validity of the isotache model, CRS oedometer tests were carried out, where the strain rate was suddenly changed and the shift of the stress caused by the change in the strain rate was measured. Using 17 different soils including intact and reconstituted specimens, the strain rate dependency was quantified in terms of $R=\Delta p_{\mathrm{r}} / p$, where $\Delta p_{\mathrm{r}}$ is the stress shift and $p$ is the stress before changing the strain rate. It was found that $R$ for all the soils in this study was broadly the same at $0 \cdot 1$, independent of the strain rate level (from $3 \times 10^{-6}$ to $3 \times 10^{-9} / \mathrm{s}$ ). However, the strain-stress relationship after changing the strain rate is not always parallel to the original relation before the changing. Two types of soil were selected for further study, OsakaMa13Re and KasaokaRe. The former followed relatively well the isotache model, and the latter was a non-isotache type. For these two clays, the incremental loading tests were performed with various incremental load ratios and durations in the loading stage prior to the incremental load. It was revealed that the strain and stress relationship for OsakaMa13Re could be interpreted by the isotache model, but KasaokaRe with $7 \mathrm{~d}$ of duration in the previous loading stage behaved differently. It is considered that this behaviour is attributed to the structuring effects that may be caused by the relatively long duration at the previous loading stage.

\section{REFERENCES}

Burland JB (1990) On the compressibility and shear strength of natural clays. Géotechnique 40(3): 329-378, http://dx.doi.org/ 10.1680/geot.1990.40.3.329.

JGS (Japanese Geotechnical Society) (2009) JGS 05222009: Method for consolidated-undrained triaxial compression test on soils. Japanese Geotechnical Society, Tokyo, Japan.
JSA (Japanese Standards Association) (2009) JIS A 1217:009: Test method for one-dimensional consolidation properties of soils using incremental loading. Japanese Standards Association, Tokyo, Japan.

Kobayashi M, Furudoi T, Suzuki S and Watabe Y (2005) Modeling of consolidation characteristics of clays for settlement prediction of Kansai International Airport. Proceedings of the Symposium of Geotechnical Aspects of Kansai International Airport, Osaka, Japan, pp. 65-76.

Leonards GA and AltschaeffI AG (1964) Compressibility of clay. Journal of Soil Mechanics (ASCE) 90(5): 133-155.

Leroueil S, Kabbaj M, Tavenas F and Bouchard R (1985) Stress-strain-strain rate relation for the compressibility of sensitive natural clays. Géotechnique 35(2): 159-180, http://dx.doi.org/10.1680/geot.1985.35.2.159.

Marques MES, Leroueil S and Almeida MSS (2002) Viscous behavior of St-Toch-de-l' Achigan clay. Canadian Geotechnical Journal 41(1): 25-38.

Seng S and Tanaka H (2012) Properties of very soft clays: a study of thixotropic hardening and behavior under low consolidation pressure. Soils and Foundations 52(2): 35-345.

Suklje L (1957) The analysis of the consolidation process by the isotache model. Proceedings of the 4th International Conference on Soil Mechanics and Foundation Engineering, London, UK, vol. 1, pp. 200-206.

Tanaka H (2005) Consolidation behavior of natural soils around pc value - long term consolidation test. Soils and Foundations 45(3): 83-96.

Tsutsumi A and Tanaka H (2011) Compressive behavior during the transition of strain rate changing. Soils and Foundations 51(5): 813-822.

Tsutsumi A and Tanaka H (2012) Combined effects of strain rate and temperature on consolidation behavior of clayey soils. Soils and Foundations 52(2): 207-215.

Watabe Y, Udaka K and Morikawa Y (2008) Strain rate effect on long-term consolidation of Osaka bay clay. Soils and Foundations 48(4): 495-509.

Watabe Y, Udaka K, Nakatani Y and Leroueil S (2012) Long-term consolidation behavior interpreted with isotaches concept for worldwide clays. Soils and Foundations 52(3): 449-464. 